$\underline{\text { Avicenna Journal of Nursing and Midwifery Care - ISSN 2676-5748 }}$

\title{
The Relationship between Teamwork and Organizational Agility in Nurses of Shahid Chamran Hospital in Saveh
}

\author{
Bita Parsa ${ }^{*}$, Majid Fatehpour ${ }^{2}$, Mahmoud Aghagoli ${ }^{3}$
}

1. PhD, Assistant Professor, Department of Management, Naser Khosrow Higher Education Institute, Iran

2. Master of Science, Instructor, Department of Management, Naser Khosrow Higher Education Institute, Iran

3. Master of Science in Business Administration, Naser Khosrow Higher Education Institute, Iran

\begin{tabular}{ll}
\hline Article Info & ABSTRACT \\
\hline
\end{tabular}

Received: 2019/07/15;

Accepted: 2019/09/13;

Published Online: 2020/01/03

10.30699/ajnmc. 28.1 .20

Original Article

Use your device to scan and read the article online

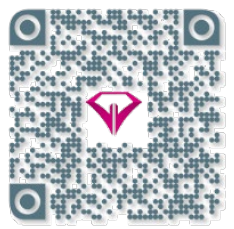

Introduction: This study aimed to determine relationship between team working and organizational agility among nurses of Shahid Chamran Hospital in Saveh, Iran.

Methods: This study was a descriptive-analytical research. The statistical population consisted of nurses who worked in the Shahid Chamran Hospital in Saveh, Iran. From whom 120 were randomly selected. The Sharifi and Zhang organizational agility standard questionnaire and the Lichoni teamwork questionnaire were used to measure the variables of the study. Data was analysed by SPSS 21 using descriptive analysis and linear multiple regression analysis at a significance level less than 0.05 .

Results: Based on the findings, ddimensions of teamwork including commitment, trust, responsibility, constructive attitude and purposefulness influenced the organizational agility in nurses $(P<0.05)$.

Conclusion: Therefore, encouraging teamwork is essential to promote organizational agility.

Keywords: Nurse, Hospital, Organizational Agility, Team work

Copyright $($ C 2020, This is an original open-access article distributed under the terms of the Creative Commons Attribution-noncommercial 4.0 International License which permits copy and redistribution of the material just in noncommercial usages with proper citation.

\section{How to Cite This Article:}

Parsa B, Fatehpour M, Aghagoli M. The Relationship between Teamwork and Organizational Agility in Nurses of Shahid Chamran Hospital in Saveh. Avicenna J Nurs Midwifery care. 2020; 28 (1) :20-26 


\title{
رابطةٌ كار تيمى با جابكى سازمانى در يرستاران بيمارستان شهيد جمران ساوه \\ بيتا پارسا"'، مجيد فاتحيور ‘، محمود آقاگلى
}

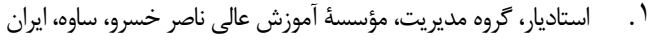

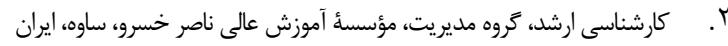

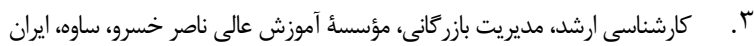

\begin{tabular}{|c|c|}
\hline جكيده & 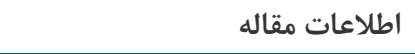 \\
\hline مقدمه: ابكىى سازمانى در پرسنل بيمارستانها كه بايد با سرعت و دقت سلامت بيماران را تامين & 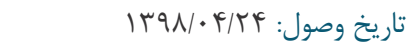 \\
\hline \multirow{2}{*}{ 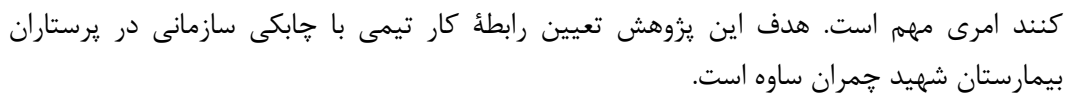 } & 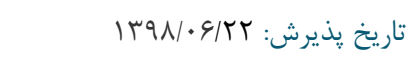 \\
\hline & انتشار آنلاين: \\
\hline \multirow{6}{*}{ 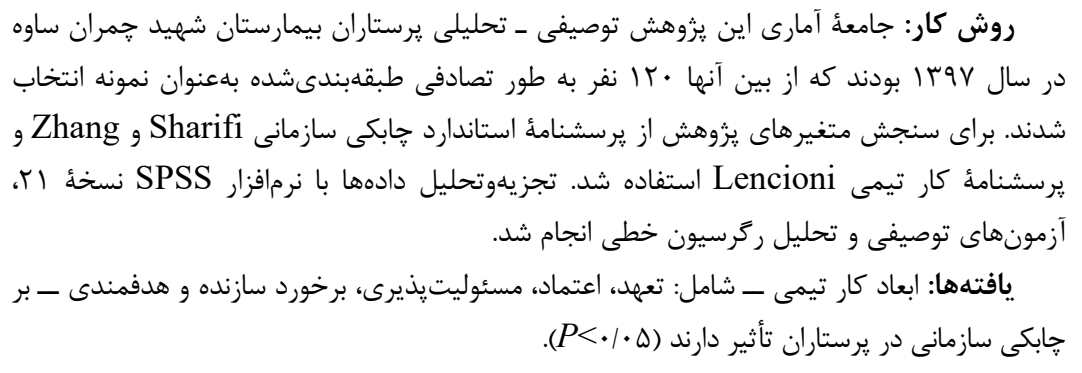 } & نو سسندهُ مسئول: \\
\hline & \\
\hline & استاديار، كروه مديريت، مؤسسهُ آموزش عالى \\
\hline & ن اصر خسرو، ساوه، ايران \\
\hline & 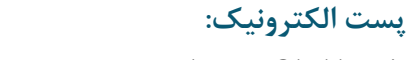 \\
\hline & b.parsa@hnkh.ac.ir \\
\hline نتيجه كيرى: براى ارتقاى حابكى سازمانى تشويق به كار تيمى ضرورى است. & \\
\hline كليدوازهها: برستار، بيمارستان، خابكى سازمانى، كار تيمى & \\
\hline
\end{tabular}

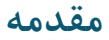

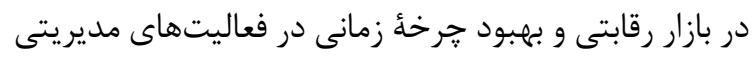

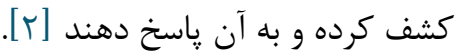

به سبب وجود فضاى شديد رقابتى سازمانها تلاش زيادى را براى حفظ و بهبود مزيتهاى رقابتى خود انجام

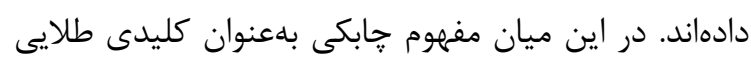

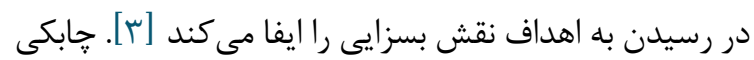

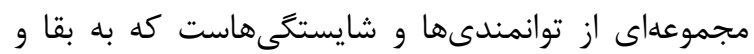

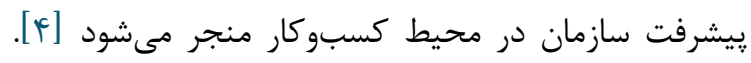

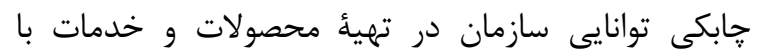
كيفيت خوب را افزايش مىدهد. بنابراين براى افزايش توان دان

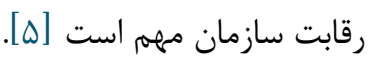
سازمانهايى كه در محيطى بسيار فعال و زويا فعاليت مى كنند همواره با تهديدهايى روبهرو مىشوند و در صورت

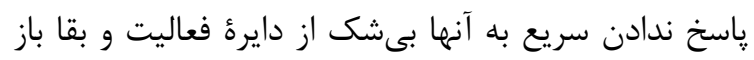

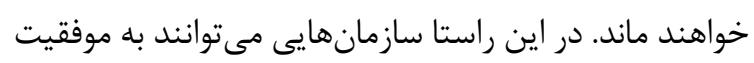
دست يابند كه از رويكردها و راهبردهاى جديد همجئون

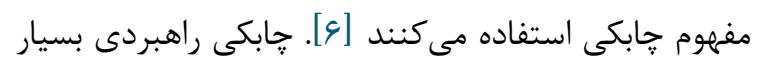

اصطلاح تيم به تعدادى از افراد با مهارتهاى مكمل اطلاق مىشود كه به هدف مشترى اهداف عملكردى و

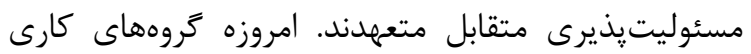

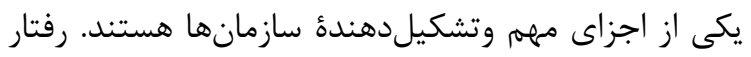

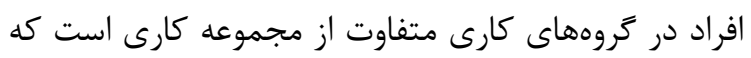

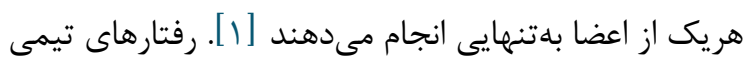

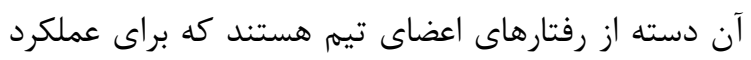

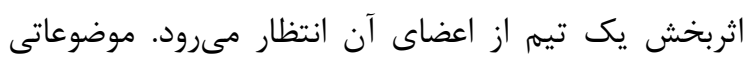
همجون گرايش به كار تيمى، وفادارى و تعهد به تيم، انس انسجام تيمى، خوداتكايى تيمى، باور به كار تيمى (Team work) و

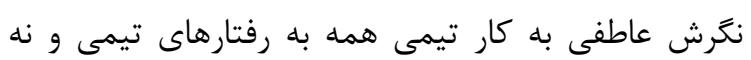
رفتارهاى وظيفهاى مربوط مىشوند [r]. امروزه با افزايش رقابت و تغييرات غيرقابل ييشبينى دينى در

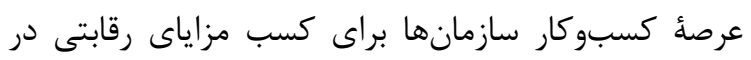
دستيابى به اهداف سازمانى و موفقيت در كسبوكار كار بايد بران

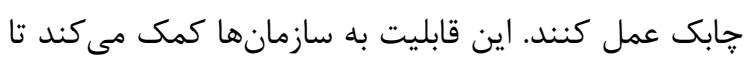
تغييرات غيرقابل ييشبينى را براى دستيابى به موقعيت بهتر 
بيمارستانهاى شهر يزد انجام دادند دريافتند كه ميانگَين يادكيرى سازمانى و جابكى در بيمارستانهاى يزد يإيينتر از

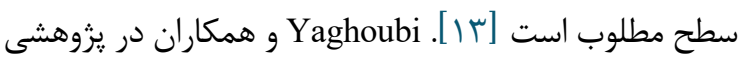
كه در سال •وץ" در اصفهان انجام دادند دريافتند كه

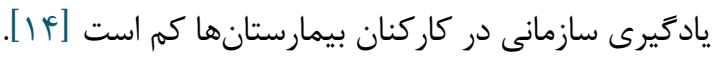

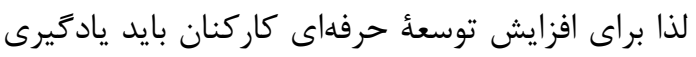

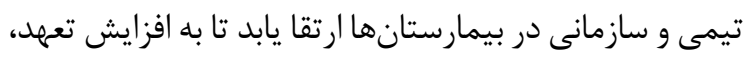

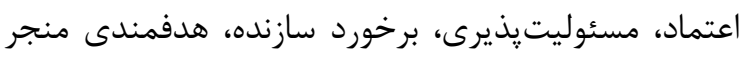

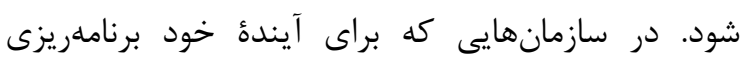

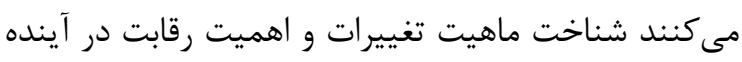

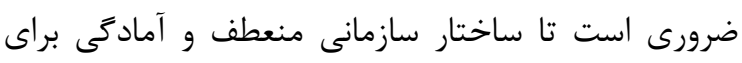

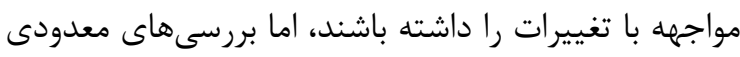

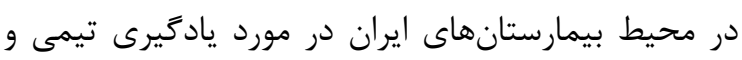

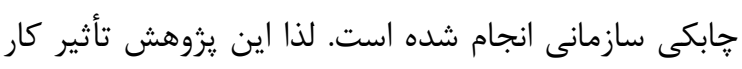

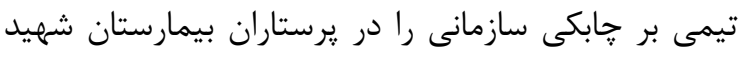

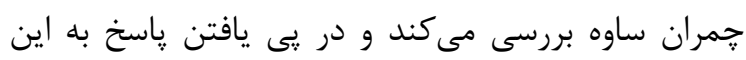

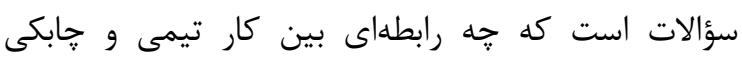

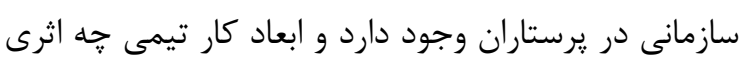
روى جابكى سازمانى دارد.

\section{روش بر رسى}

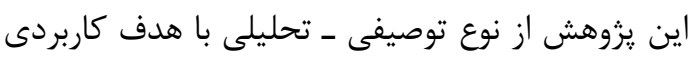

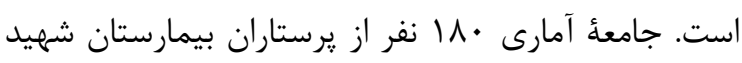

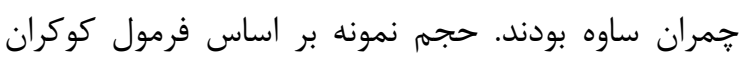
محاسبه شد.

$$
\mathrm{n}=\frac{N z^{2} p q}{N d^{2}+z^{2} p q}
$$

$\mathrm{N}=1 \wedge \cdot, \mathrm{z}=1 / 94, \mathrm{p}=\mathrm{q}=\cdot / \cdot 9, \mathrm{~d}(\mathrm{~d})=\cdot / \cdot \Delta$

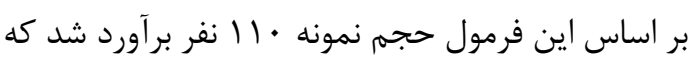

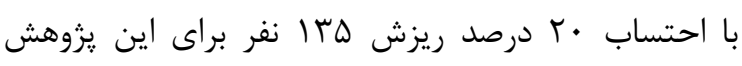

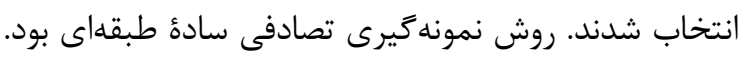

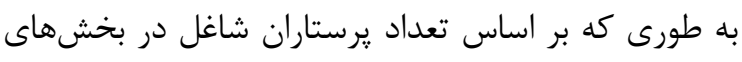

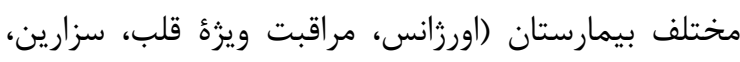

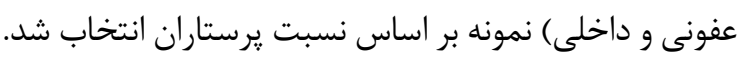

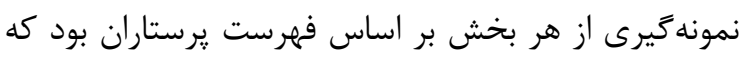

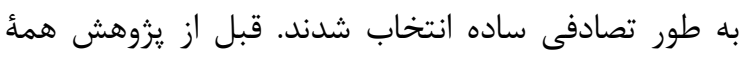

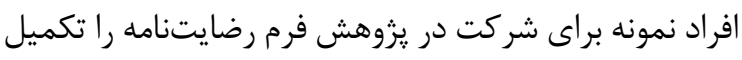

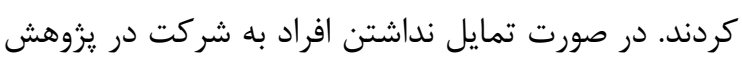

كليدى در راستاى دريافت سريع نيازهاى مشتريان و ارائئ

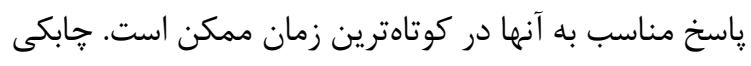

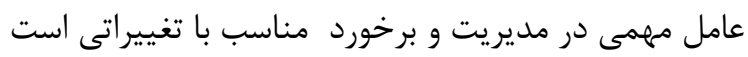

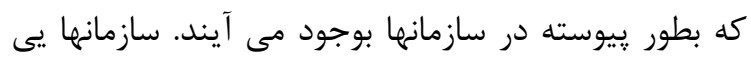
كه جابكى مناسب داشته باشند مى توانند در شرايط تغيير

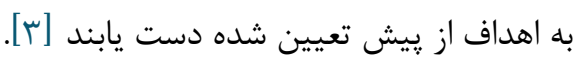

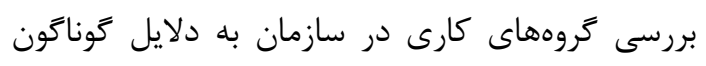

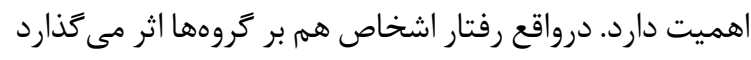

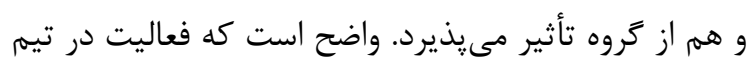

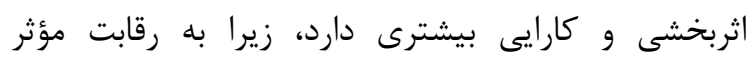

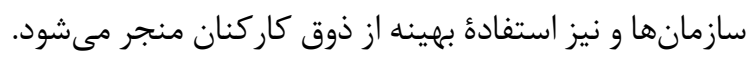

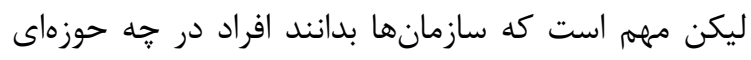

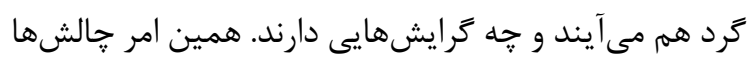

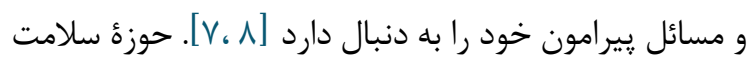
به دليل يويايى بالايى كه دارد در مديريت دانش اهميت

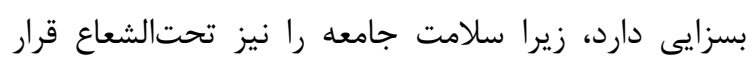

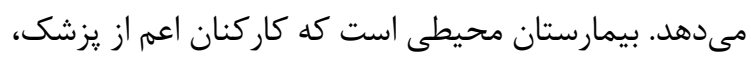

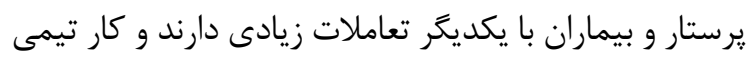

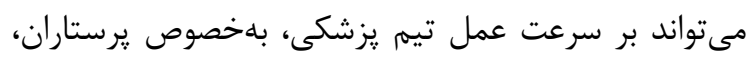

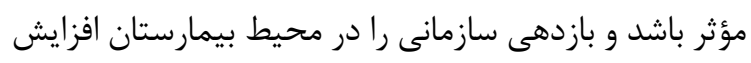

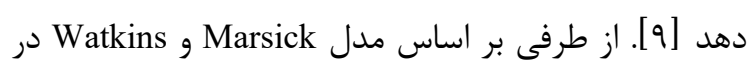

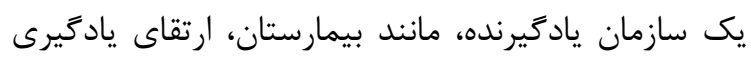

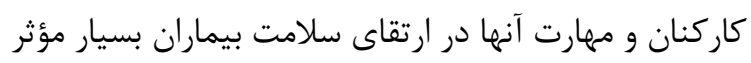
است. بررسىها نشان مىدهد كه يادكيرى تيمى مى تواند

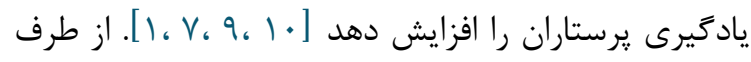

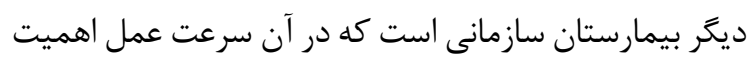

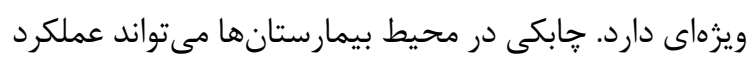

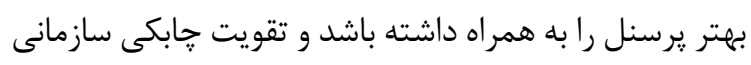

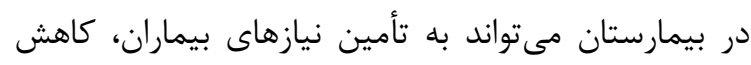

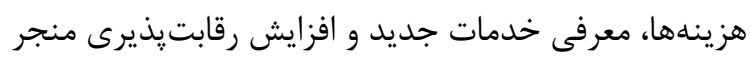

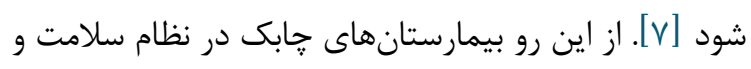

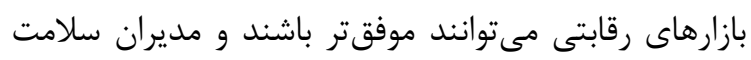

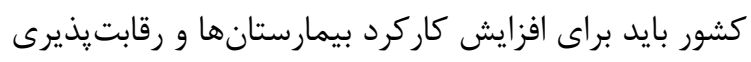
آنها تلاش كنند [11] Yarmohammadian

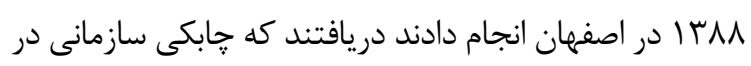

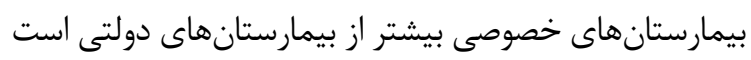

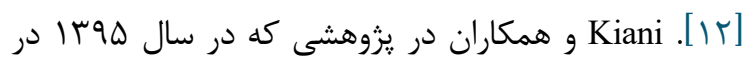


برخورد سازنده AV/ • و هدفمندى V9/ • بود و پايايى مناسب يرسشنامه را نشان مى دهد.

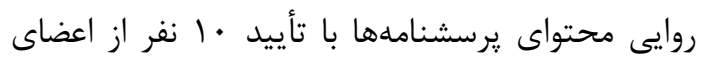

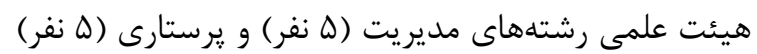

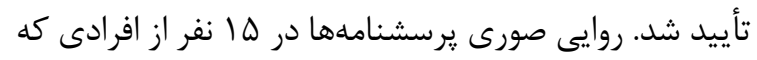

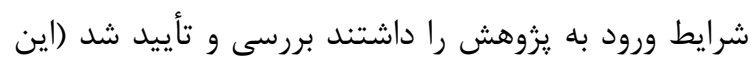
افراد وارد يزوهش نشدند).

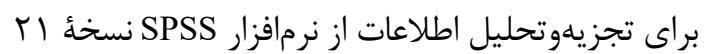
(SPSS Inc., Chicago, Ill. USA)

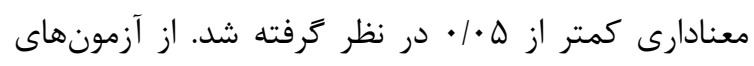

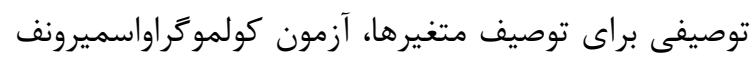

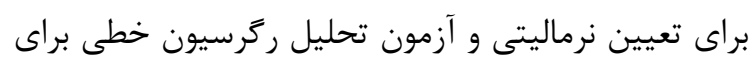
آزمون فرضيات استفاده شد. ترين

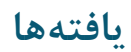

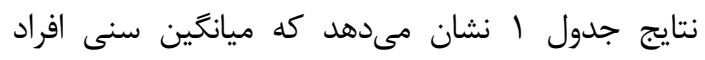

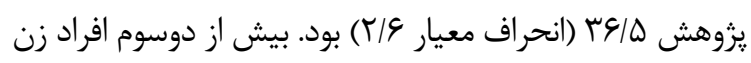

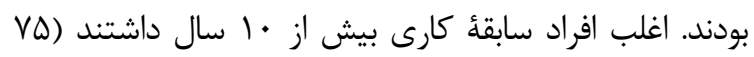

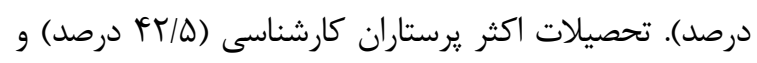

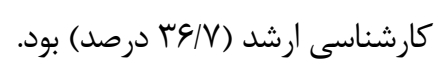

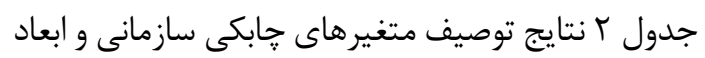

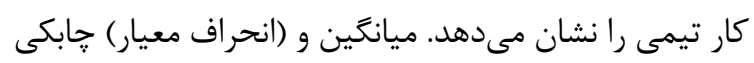

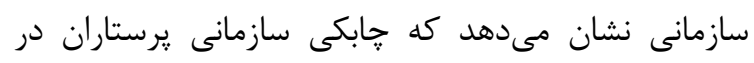

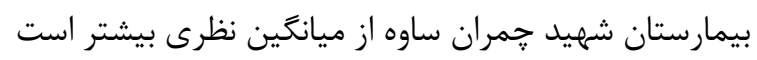
و وضعيت خوبى دارد. ميانكَين و انحراف معيارهاى ابعاد كار تيمى در همأ دأ

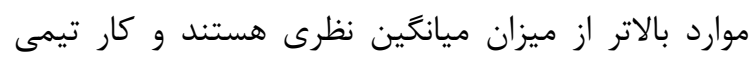

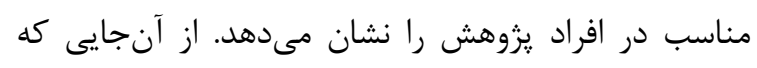

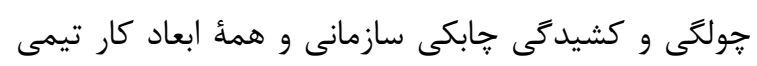

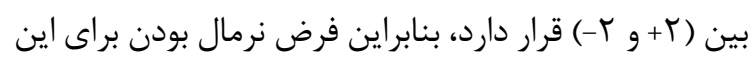

$$
\text { متغيرها تأييد مىشود (جدول ب) قرار دارد بناير اين فرض }
$$

نتايج آزمون تحليل ركرسيون خطى در جدول ب آمده

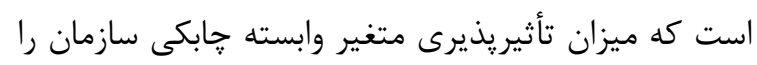

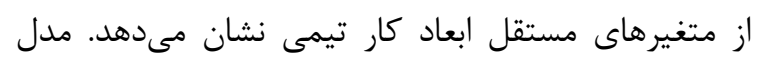

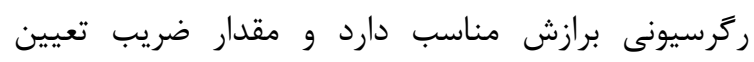

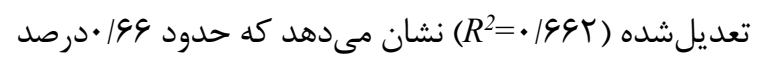
از تغييرات جابكى سازمانى توسط متغيرهاى ابعاد كار تيمى قابل تبيين است.
فرد واجد شرايط ديگرى جايگزين آنها مىشد. سيس

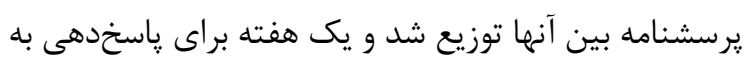

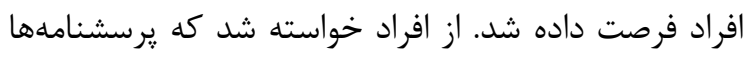

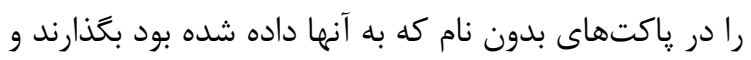

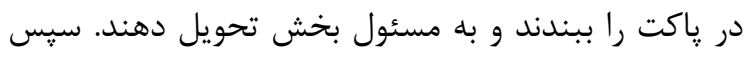

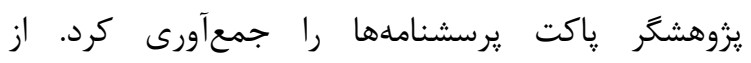

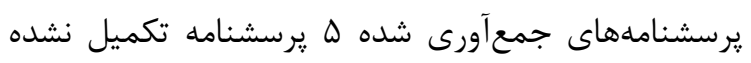

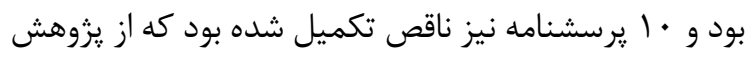

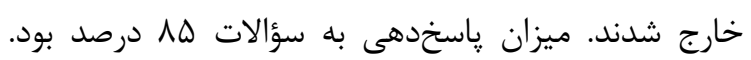

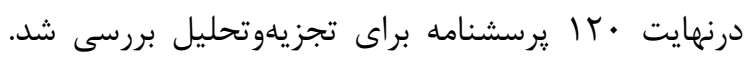

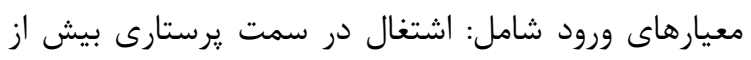

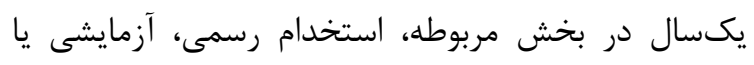

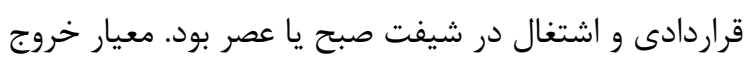

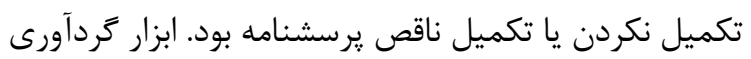

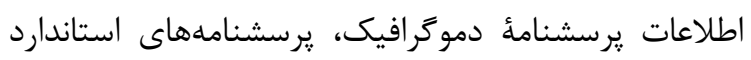

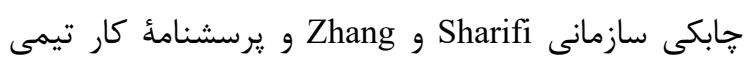
Lencioni

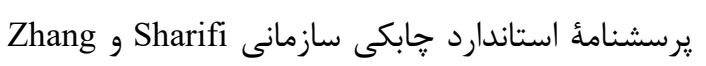

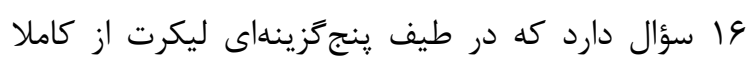

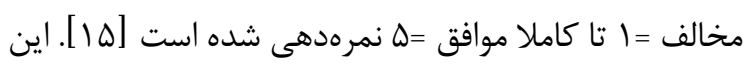

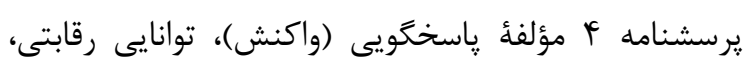

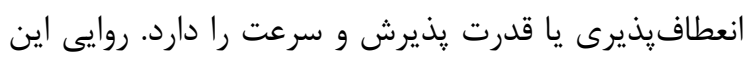

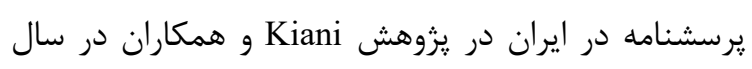

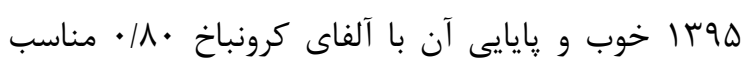

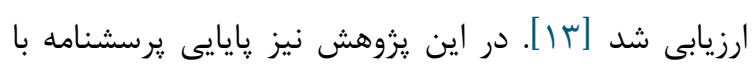

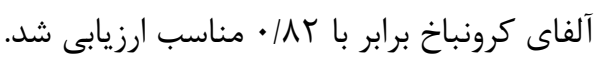

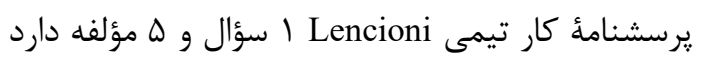

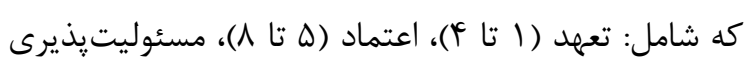

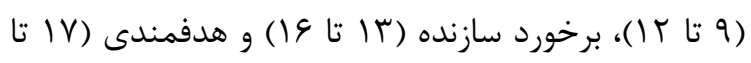

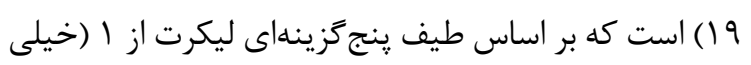

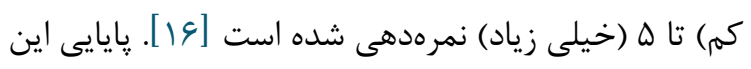

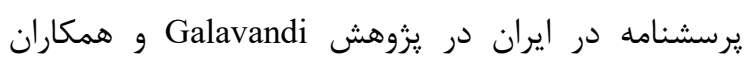

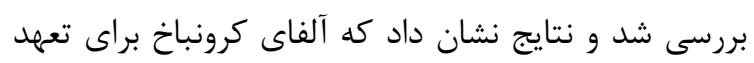

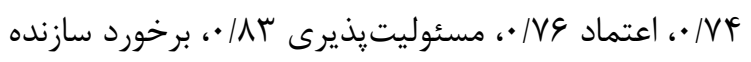

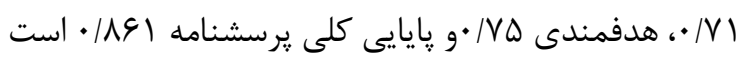

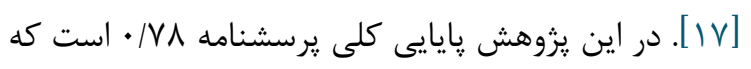

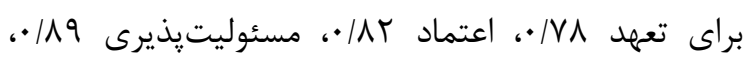


جدول ا. توصيف جمعيتشناختى افراد يزوهش

\begin{tabular}{|c|c|c|c|}
\hline درصد & تعداد & سطوح & متغير \\
\hline$V / \Delta$ & 9 & $r \cdot-r \cdot$ & \multirow{5}{*}{ سن } \\
\hline$\Delta r / \Delta$ & א & $\boldsymbol{f} \cdot-r$. & \\
\hline$r q / r$ & FV & $\Delta \cdot-f \cdot$ & \\
\hline$\cdot / 1$ & 1 & G. - Q. & \\
\hline $1 \ldots$ & $\pi$. & كل & \\
\hline $\mathrm{V} / \mathrm{d}$ & 94 & زن & \multirow{3}{*}{ جنسيت } \\
\hline$r T / D$ & re & مرد & \\
\hline $1 \cdots$ & Ir. & كل & \\
\hline$r / \mathcal{F}$ & f & زير هـ & \multirow{6}{*}{ سابقهُ خدمت } \\
\hline $19 / \pi$ & rr & $1 \cdot-\Delta$ & \\
\hline $01 / V$ & GT & $10-1$ & \\
\hline$r \Delta / \cdot$ & $r$. & $r \cdot-10$ & \\
\hline$\cdot / 1$ & 1 & بالاى ·r & \\
\hline $1 \ldots$ & Ir. & كل & \\
\hline$r \cdot / \Lambda$ & ra & كاردانى & \multirow{4}{*}{ سطح تحصيلات } \\
\hline FT/D & QI & كارشناسى & \\
\hline$r g / V$ & fq & كارشناسى ارشد & \\
\hline $1 \ldots$ & $\pi$. & كل & \\
\hline
\end{tabular}

جدول r. توصيف جابكى سازمانى و ابعاد كار تيمى در يرستاران بيمارستان شهيد جمران ساوه

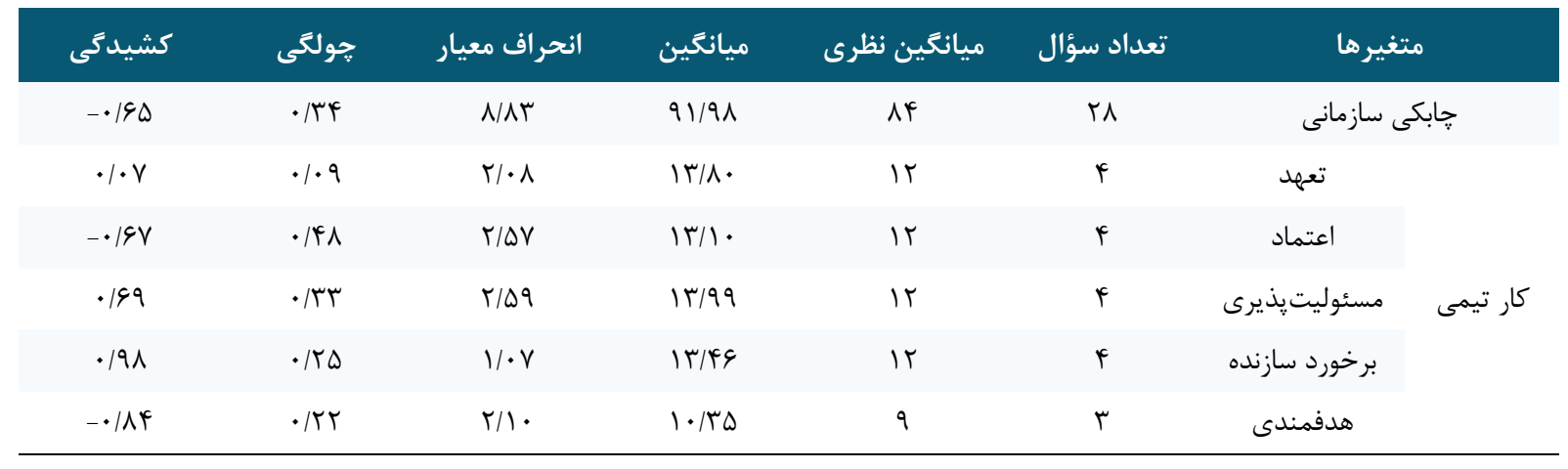

جدول r. مدل تحليل رَر سيون خطى

\begin{tabular}{|c|c|c|c|c|c|}
\hline سطح معنادارى & $\mathbf{F}$ & تعديلشده $R^{2}$ & $R^{2}$ & ضريب همبستكى (r) & مدل رترسيون \\
\hline
\end{tabular}

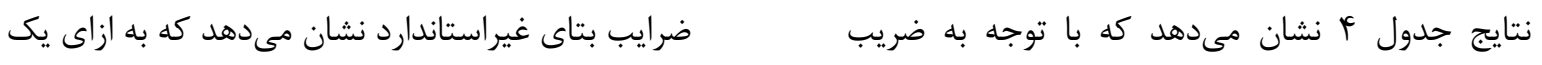

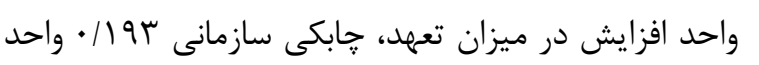
افزايش مىيابد. به ازاى يك واحد در ميزان اعتماد، جابكى دئى

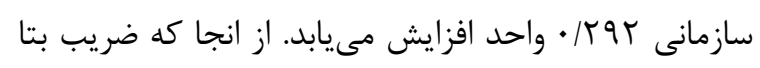
غير استاندارد در تمام موارد مثبت است در تمامى موارد ابعاد كار تيمى با افزايش جابكى همراه مى باشد.

دورة ب T شمارة I - فروردين و ارديبهشت
استانداردشده م، تغييرات جابكى سازمان بلهترتيب تأثير از

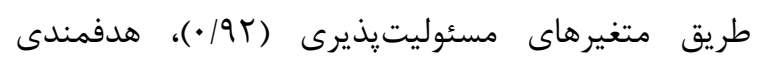

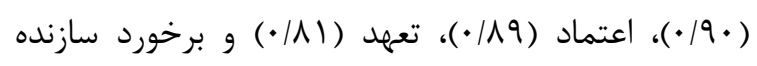

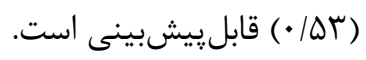




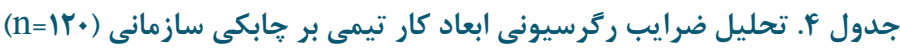

\begin{tabular}{|c|c|c|c|c|c|}
\hline سطح معنادارى & $\mathbf{t}$ & بتاى استاندارد & خطاى استاندارد & ضرايب استاندار رنشده & مدل رَر سيون \\
\hline$\cdot 1 \cdot \cdot 1$ & T/MFF & & $1 / 199$ & $r / q \cdot q$ & ضريب ثابت \\
\hline$\cdot 1 \cdot \cdot 1$ & $10 / T 19$ & $\cdot|\Lambda| F$ & (11 &.$/ 194$ & تعهد \\
\hline$\cdot 1 \cdot \cdot 1$ & $T Y / T \wedge \Lambda$ & $\cdot 1199$ & $\cdot / \cdot 14$ & . /rqr & اعتماد \\
\hline$\cdot 1 \cdot \cdot 1$ & rg/IGY &.$/ 9 T F$ & $\cdot 1 \cdot 1$ & $\cdot \mid r V I$ & مسئوليتيذيرى \\
\hline$\cdot 1 \cdot \cdot 1$ & G/AVG & $\cdot / \Delta T \Delta$ & $\cdot 1 \cdot \cdot 9$ & .1 .90 & برخورد سازنده \\
\hline$\cdot / \cdot 1$ & Tr/V.. & $\cdot 19 \cdot r$ & $\cdot 1 \cdot 9$ & $\cdot / r \mid \Delta$ & هدفمندى \\
\hline
\end{tabular}

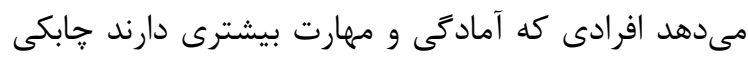
بحث

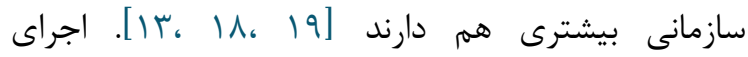

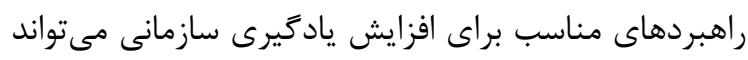

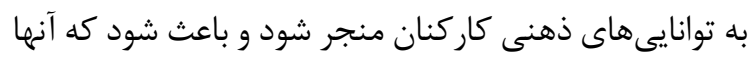
در شرايط تغيير قدرت واكنش و ياسخكويى بيشترى داشته

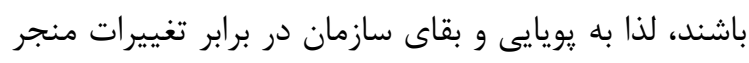

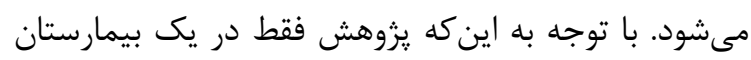
انجام شد امكان تعميم نتايج به بيمارستانهاى دئر دئر كاهش

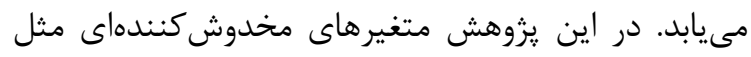

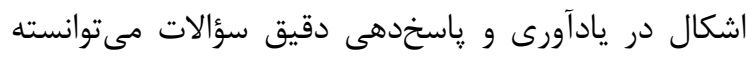

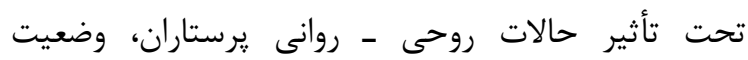

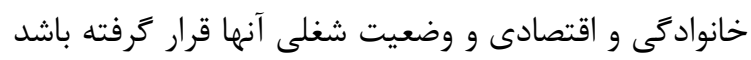

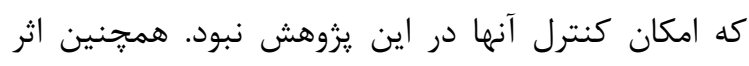

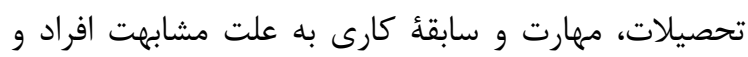

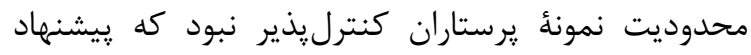

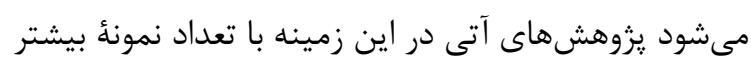
و در بيمارستانهاى بيشترى انجام شود.

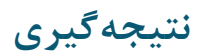

يافتههاى اين يزوهش نشان مىدهد كه كار تيمى به

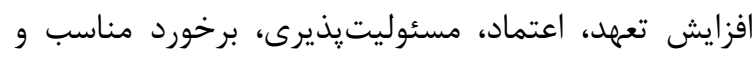

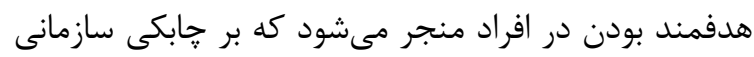

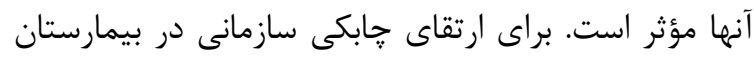

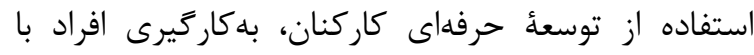

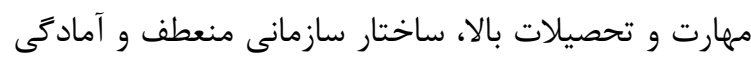
براى واكنش در مقابل تغييرات لازم است.

\section{سياسگزارى}

اين مقاله حاصل پاياننامٔ كارشناسى ارشد مديريت

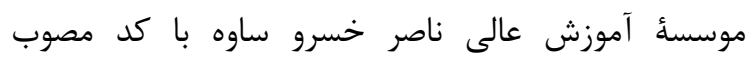

وضعيت توصيفى متغير خابكى نشان مى دهد كه جابكى

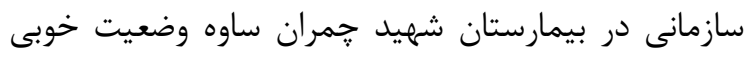

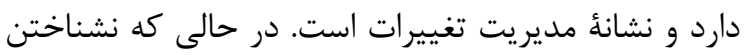
تغييرات و ياسخ سريع به آنها در يروهش

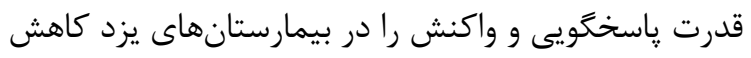

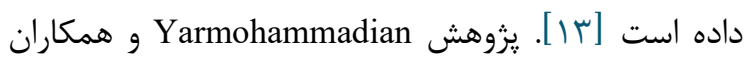
در شهر اصفهان نشان مىدهد كه جابكى سازمانى در

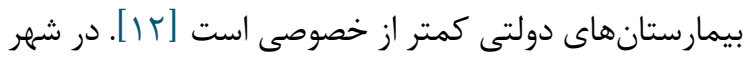

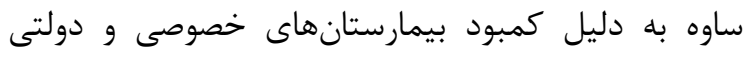

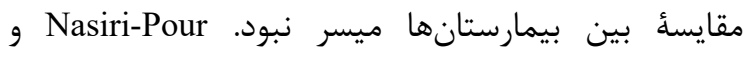

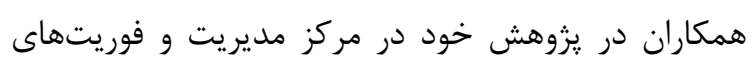

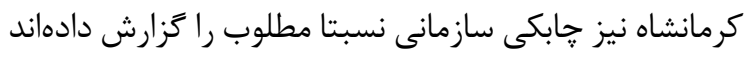

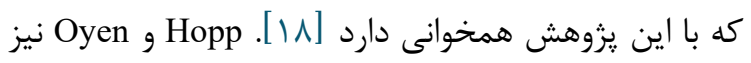
كزارش كردهاند در سازمانهايى كه كاركنان آنها دورههاى

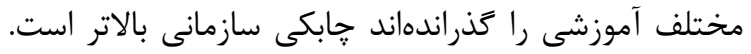

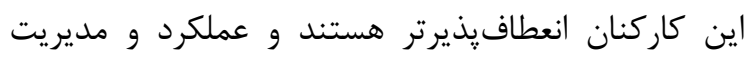

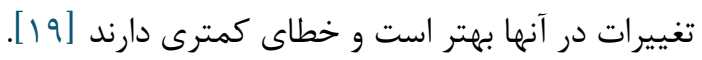

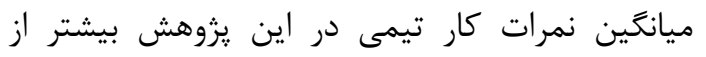
متوسط كزارش شد كه با يزوهش بaghoubi و همكاران

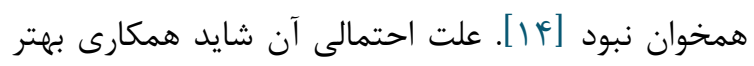

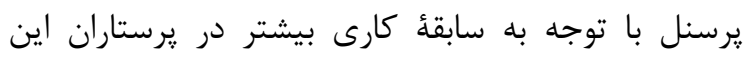

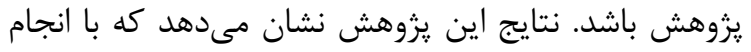

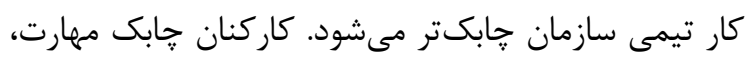

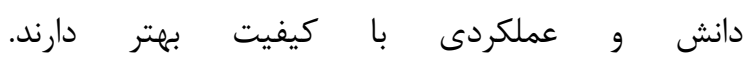
Yarmohammadian

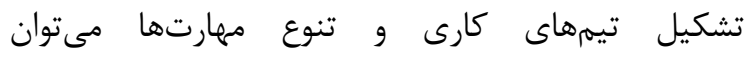

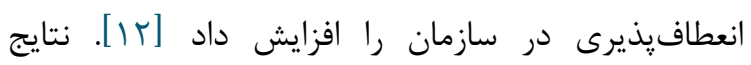
يزوهشهاى ديكر نيز با اين يزوهش همخوانى دارد و نشان ران 


$$
\text { منين نويسندگان هيجزونه تعارضى در منافع وجود ندارد }
$$

\section{References}

1. Marsick VJ, Watkins $\mathrm{K}$. Informal and Incidental Learning in the Workplace (Routledge Revivals). Routledge; $2015 \quad$ Jun 11. [DOI: $10.4324 / 9781315715926$ ]

2. Aghaee R, Aghaee A, Mohammad Hoseini Najizadeh R. Key Effective Factors on Agile Maintenance in Vehicle Industry Using fuzzy Delphi Method and Fuzzy Dematel. Industrial Management Journal. 2015 Dec 22;7(4):641-72.

3. Nijssen M, Paauwe J. HRM in Turbulent Times: How to Achieve Organizational Agility? The International Journal of Human Resource Management. 2012 Sep 1;23(16):3315-35..

\section{[DOI:10.1080/09585192.2012.689160]}

4. Worley CG, Lawler EE. Agility and Organization Design: A Diagnostic Framework. Organizational Dynamics. $2010 \quad$ Apr 1;39(2):194-204. [DOI:10.1016/j.orgdyn.2010.01.006]

5. Solaja OM, Ogunola AA. Leadership Style and Multigenerational Workforce: A Call for Workplace Agility in Nigerian Public Organizations. Leadership. 2016;21:46-56

6. Kitzmiller R, Hunt E, Sproat SB. Adopting Best Practices:" Agility" Moves from Software Development to Healthcare Project Management. CIN: Computers, Informatics, Nursing. 2006 Mar 1;24(2):75-82. [DOI:10.1097/00024665-200603000-00005] [PMID]

7. Dyer L, Shafer RA. Dynamic Organizations: Achieving Marketplace and Organizational Agility with People. . Cahrs Working Paper Series. 2003:27.

8. Vartanian HK, Bobay KL, Weiss ME. Nurses' Perceptions of Sustainability of Magnet ${ }^{\circledR}$ Efforts. JONA: The Journal of Nursing Administration. 2013 Mar 1;43(3):166-71. [DOI:10.1097/NNA.0b013e318283dca7] [PMID]

9. Marsick VJ, Watkins KE. Demonstrating the Value of an Organization's Learning Culture: the Dimensions of the Learning Organization Questionnaire. Advances in developing human resources. 2003 May;5(2):132-51. [DOI:10.1177/1523422303005002002]

10. Bahadori $\mathrm{M}$, Hamouzadeh $\mathrm{P}$, Qodoosinejad J, Yousefvand M. Organizational learning capabilities of nurses in iran. International Journal of Global Business and Management Research 2012;44(2):48-54.

11. Grol R, Baker R, Moss F. Quality Improvement Research: Understanding the Science of Change in Health Care. Quality and Safety in Health Care.

$$
\text { צr رابطهُ كار تيمى با جابكى سازمانى در يرستاران }
$$

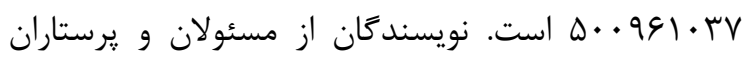
بيمارستان شهيد جمران كه در انجام اين :زئوهش مشاركت كردهاند، تشكر مى كنند.

$$
\text { تعارض در منافع }
$$

2002;11(2):110-1. [PMID] [PMCID]

[DOI:10.1136/qhc.11.2.110]

12. Yarmohammadian $M$, Samuie $R$, Khodaiary $R$, Ayoobian A, Bagherian H. The Agility of Esfehan hospitals. Health Inf Manag. 2011;8:112.

13. Kiani M, Bahrami M, FalahZadeh H, Montazeralfaraj R, Mohammad Zadeh M. Evaluation of organizational intelligence, organizational agility in teaching hospitals University of Medical Sciences Yazd city. Journal Tolooebehdasht Sci. 2017;15(5):95-108.

14. Yaghoubi M, Karimi S, Javadi M, Nikbakht A. A Correlation Study on Organization Learning and Knowledge Management in Staffs in Selected Hospitals of Isfahan University of Medical Sciences. Journal of Health Administration. 2011 Jan 10;13(42):65-75.

15. Sharifi $H$, Zhang Z. Agile Manufacturing in PracticeApplication of a Methodology. International Journal of Operations \& Production Management. 2001 May 9;21(5-6):772-94. [DOI:10.1108/01443570110390462]

16. Lencioni P. The Five Dysfunctions of a Team: A Leadership Fable . San Francisco Jossey-Bass Inc. 2002.

17. Galavandi H, Kabiri A, Soltanzadeh VA. Study of the Relationship between Social Responsibility and Teamwork among the Staff of Urmia University. Journals of Applied Sociology. 2014;25(1):111-20 .

18. Nasiri-Pour A, Raeissi P, Mahbobi M. Border Hospital Readiness in Handling Border Related crisis in Kermanshah Province, Iran, 2007. Journal of Health Administration. 2007 Jul 10;10(28):41-8.

19. Hopp WJ, OYEN MP. Agile Workforce Evaluation: a Framework for Cross-Training and Coordination. slie Transactions. 2004 Oct 1;36(10):919-40. [DOI: $10.1080 / 07408170490487759]$ 